\title{
Article \\ Trafficking of Women in Mexico and Their Health Risk: Issues and Problems
}

\author{
Arun Kumar Acharya \\ Autonomous University of Nuevo Leon, 64930 Monterrey, Mexico; E-Mail: arun.kumara@uanl.mx
}

Submitted: 1 September 2014 | In Revised Form: 8 December 2014 | Accepted: 10 December 2014 |

Published: 23 February 2015

\begin{abstract}
Trafficking in women is one of the most corrosive forms of human rights violation. It results in the gradual destruction of a woman's personal identity and her right to live as a free human. The victim is subjected to violence, humiliation and violation of her personal integrity, which may result in life threatening diseases like HIV/AIDS, STDs or lifelong trauma, drug addiction or personality disintegration. It can also be seen as denial of the right to liberty and security of the person, and the right to freedom from torture, violence, cruelty or degrading treatment. Over the last few decades, international trafficking of women has been given more attention by researchers. However at present internal trafficking is drawing more attention and concern from researchers. The complexity of obtaining visas and strict patrolling on international borders has caused a boom of internal trafficking around the world. Thus, the current paper aims to investigate trafficking of women for sexual exploitation including the recruitment process, methods of trafficking and working conditions of the victims; as well as to explore the determinants of sexual violence and its impact on the health of trafficked women in Monterrey, Mexico. For the present study a total of 60 women were interviewed using a snowball method between 2007 and 2013.
\end{abstract}

\section{Keywords}

femicide; life threatening diseases; Mexico; sexual exploitation; trafficking in women

\section{Issue}

This article is part of the special issue "Perspectives on Human Trafficking and Modern Forms of Slavery", edited by Siddharth Kara (Harvard Kennedy School of Government, USA).

(C) 2015 by the author; licensee Cogitatio (Lisbon, Portugal). This article is licensed under a Creative Commons Attribution 4.0 International License (CC BY).

\section{Introduction}

Trafficking of persons for sexual exploitation or forced labour, both within a country and across international borders is one of the most lucrative and fastest growing types of organized crime (Ribando, 2005; United Nations Office on Drugs and Crime [UNODC], 2012). According to a U.S. State Department estimation, some $600,000-800,000$ people worldwide are trafficked across borders for forced labour, domestic servitude, or sexual exploitation each year. This figure does not include victims who are trafficked domestically and, if included, this would raise to the total by 2 million to 4 million (U.S. State Department, 2014). The International Labour Organization (ILO) estimates that globally 2.4 million people have been trafficked for forced labour (ILO, 2008). Most observers concur that the majority of trafficking victims are women and children placed in commercial sexual exploitation.

Trafficking of persons affects almost every country and region in the world and has been the focus of world attention since 1990s. Regardless of international commitments to diminishing trafficking in women, studies show that the phenomenon is increasing as the disparity between wealth and poverty grows between and within the nations (Barner, Okech, \& Meghan, 2014). According to Demir (2003), poverty disproportionately affects women. It is not surprising that, following trends in migration, women are pushed to migrate with a hope of acquiring economic security for 
themselves and their families. Although the push and pull factors of migration are similar for men and women, their migration experience can differ greatly. For millions of women, this economic migration ends in sexual exploitation and debt bondage (ILO, 2012).

Today, in our globalized world, trafficking of women has increased and has become a major human rights, migration and gender concern (Heyzer, 2002). In the year 2000, the United Nations, in its Protocol to Prevent, Suppress and Punish Trafficking in Persons, adopted in Palermo, defines human trafficking in Article 3 as:

"the recruitment, transportation, harbouring or receipt of persons, by means of the threat or use of force or other forms of coercion, of abduction, of fraud, of deception, of the abuse of power or of a position of vulnerability or of the giving or receiving of payments or benefits to achieve the consent of a person having control over another person, for the purpose of exploitation. Exploitation should include sexual exploitation, forced labour, slavery, servitude and removal of organs." (United Nations General Assembly, 2000)

Trafficking of women is one of the most corrosive forms of human rights violations. It results in the gradual destruction of a woman's personal identity, and her right to live as a free human. The victim is subjected to violence, humiliation and violation of personal integrity which may result in life threatening diseases like HIV/AIDS, STD or lifelong trauma, drug addiction or personality disintegration. It can also be seen as the denial of the right to liberty and security of the person, and the right to freedom from torture, violence, cruelty or degrading treatment.

According to the 2014 Trafficking in Persons Report, Mexico is an origin, transit and destination country for trafficking of women (U.S. State Department, 2014), is a social and public health problem in the country. Likewise, a study conducted on human trafficking by the National Citizen Observatory (ONC) over a period of four years in the 31 Mexican states and the Federal District, indicates that in just 16 states a total of 846 victims were reported, while the rest failed to provide information (ONC, 2014).

Most of the literature on trafficking of women in Mexico shows that the United States is a major destination (U.S. State Department, 2014; Walters \& Davis, 2011). Women and girls migrate illegally and are then at the mercy of traffickers. Many are raped and murdered (O'Neill, 2010). Coyotes who transport people across Mexico-USA border are aware of the fact that neither the victims nor their families will report these crimes, since the victims themselves are at risk of felony charges for illegal entry into United States (O'Neill, 2010; Shahani, 2013). Pimps often work in concert with coyotes. In a scenario of brutal exploitation, coyotes transport vic- tims from Mexico to the United States for reduced fees by sexually assaulting and prostituting the women as payment for passage (Farley, 2012). In 2003, Hernandez studied trafficking of Mexican girls to brothels near San Diego. Over a ten year period, hundreds of girls aged between 12 and 18 were either kidnapped or tricked from rural Mexico to the US border by traffickers or pimps.

Azaola's (2000) study, Infancia Robada (Stolen Childhood), noted that 16,000 girls and boys in Mexico were sexually exploited through networks involving immigrants, military personnel, police, governmental officials and businessmen. According to Castillo, Rangel Gómez and Delgado (1999), women who fall into sex trafficking networks and prostitution are mostly from rural areas, and have suffered from extreme poverty and family violence. In his study, Jordan (2000) underlines that the subordination of women and male supremacy (macho culture) mean women are regarded as "sexual objects". Hadden (2002) states that during 2000 and 2002, around 135,000 Mexican children were kidnapped and forced into prostitution and pornography in different Mexican cities.

Over the last decade, the international trafficking of women from Mexico to United States has declined due to the complexity of obtaining visas and strict patrolling on international borders, which has caused a boom in internal trafficking within Mexico (Hindman, 2009; Hughes \& Denisova, 2003; Rusev, 2013). For example, Acharya and Stevanato's (2005) study indicates that nearly 10,000 young girls and women are trafficked annually in Mexico to six cities: Cancun, Acapulco, Mexico City, Tijuana, Ciudad Juarez and Monterrey, for the purpose of sexual exploitation. The same study underlines that for every 10 trafficked women in Mexico, 7 are trafficked inside the country and 3 are taken out of the country to the USA and elsewhere.

In this regard, during the last few years Monterrey has become an important destination point for sex trafficking in Mexico. Though there are a few studies, for example those of Méndez (2006) and Cacho (2010), which indicate that every year large numbers of women are forced into prostitution through an organized trafficking networks, none of these studies has provided a detailed explanation of the dynamics and complexity of the problem. Thus, the current paper aims to: (1) investigate the trafficking of women for sexual exploitation, including the recruitment process, methods of trafficking and working conditions of the victims; (2) explore the determinants of sexual violence and its impact on the health of trafficked women in Monterrey city, Mexico.

\section{Conceptual and Methodological Approaches to Trafficking of Women}

Trafficking of women has been a feminist issue since the beginning of the $20^{\text {th }}$ century, when advocates for 
change like Josephine Butler ${ }^{1}$ fought against the white slave trade. They recognized that women and girls form the majority of all victims of trafficking. Recently the problem has come onto the international agenda. This process has been assisted by a widening of the focus to encompass trafficking for bonded labour in sweatshops, domestic work, adoption and marriage, as well as prostitution (Wennerholm, 2002). Now, trafficking is considered to be the second largest source of profit for organized crime, behind only drugs and gun running, generating billion of dollars annually (U.S. State Department, 2014).

Trafficking occurs both within domestic borders and across countries, regions, and continents. Countries of origin, transit, and destination are intertwined and overlap, where a single country may export women, girls and boys abroad, it may also temporarily harbour arrivals from other countries and be the final destination for others. In America, women are mostly trafficked from Colombia, Venezuela, El Salvador, Honduras, Guatemala and Mexico to the United States and Canada, where Mexico acts as the main transitional node for the other Central and South American countries and as a destination node for the Central American countries (Timothy, 2001). The main purpose of trafficking is to sell women into the sex industry as sex workers, while they are also trafficked for domestic work and other forms of bonded labour (ILO, 2012).

The World Health Organization (WHO, 2012) and Marjan Wijers (1997) identified, that the trafficking of women is a type of violence against women, which involves recruitment and/or transportation of a woman within and across national borders for work or services by means of violence or threat of violence, abuse of authority or dominant position in debt bondage, deception and other forms of coercion. Yet the Budapest Group (1996) highlight that the trafficking of women does not necessarily involve direct coercion, but nonetheless it is a violation of human dignity and fundamental rights, and constitutes abuse of a woman's vulnerable situation, making them dependent and treating them as trade products rather than as human beings.

The Department of Foreign Affairs and International Trade (DFAIT) of Canada (2000), states that traffickers retain control over the migrant through force, fraud or coercion or, typically in the sex industry, through forced labour or other practices similar to slavery. Martin (2002) defines trafficking as giving a person the status of a slave; trafficking in human beings who are already slaves, including those who sell their own freedom or that of a dependent person or child; and the transfer of human beings who are in a relationship

\footnotetext{
1 Josephine Butler (1828-1906) a strong religious convictions and the nineteenth-century feminist, who withstand the onslaught of abuse that she received from those both inside and outside of the woman's movement.
}

of slavery or another similarly dependent relationship. Thus it is a form of slavery, where people are:

- $\quad$ forced to work through the threat or use of violence;

- $\quad$ owned or controlled by an 'employer' usually through mental, physical, or threatened abuse;

- dehumanized, treated as a commodity or even bought and sold as "property"; physically constrained or having restriction placed on their freedom of movement and freedom to change employment (Herzfeld, 2002).

UNODC (2012) defines three basic elements of trafficking: 1 . the process, 2 . the means and 3 . the purpose (see Table 1). According to UNODC, trafficking takes place through a combination of these three constituent elements, rather than the individual components, although in some cases these individual elements will constitute criminal offences independently.

Table 1. Process, means and purpose of human trafficking.

\begin{tabular}{lll}
\hline Process & Means & Purpose \\
\hline Recruitment & Threat, Force, & Exploitation \\
Transportation & Coercion, & which includes: \\
Transfer & Abduction, & a) Prostitution \\
Harbouring & Fraud, & and other forms \\
Receipt of & Deception, & of sexual \\
persons & Abuse of & exploitation \\
& power, Abuse & b) Forced \\
& of vulnerability, & labour and \\
& Giving and & services \\
& receiving of & c) Slavery and \\
& payments & similar practices \\
& & d) Involuntary \\
& & servitude \\
& & e) Removal of \\
& & organs \\
\end{tabular}

Source: elaborated by the author.

Therefore, trafficking is the movement and/or transportation of persons through the use of violence or the threat of violence, abuse of authority or dominant position, deception or other forms of coercion, for the purpose of exploiting them sexually or economically for the profit or advantage of other persons, such as recruiters, procurers, traffickers, intermediaries, brothel owners and other employers, customers, or crime syndicates, which can be considered according to following conditions:

- selling of a woman for material benefits,

- migration to an unfamiliar region where an international border is crossed (but not always), 
- an intermediary - the trafficker(s)-is involved in movements of the migrants,

- recruitment and transportation of migrants or disposition of such migrants on the way or after arrival is accomplished through illicit or abusive means, and profits of the traffickers from such activities in term of economic or other personal gain.

\section{Methodology}

Trafficked women are treated as a hidden population for whom it is extremely difficult to establish a reliable sampling frame. This tends to make randomized sampling strategies unsuitable. Thus, a snowball sampling technique was used during this fieldwork. Interviews with trafficked women were carried out in two steps. The first step involves obtaining contact with key informant and in the second step trafficked women were interviewed.

\subsection{Step 1: Information from Key Informant}

Zheng (2013) stats that if a researcher is local and personally knows any of those working in the establishment, the mutual trust between them could make it far easier for the researcher to access the establishment. Taking this into consideration, first I contacted to a graduate degree student named "Olaf" at my own university (Autonomous University of Nuevo León) for collaboration with project. Olaf was also working as a part time barman in a brothel and had good knowledge of the area and business of the downtown region of Monterey City. When I discussed about the project with Ola, he agreed to try to help, but as it is difficult for him to move from one place to another, he warned that might not be able to locate many trafficked women. After few months, Olaf contacted me by telephone and gave me information about a trafficked woman and the name of the brothel where she was working.

\subsection{Step 2: Interviewing Trafficked Women}

After obtaining the information, we (myself and Francisco Ontiveros, a postgraduate student at the Institute of Social Sciences of the Autonomous University of Nuevo León) went to the designated brothel and contacted the woman, informed her about our study and mentioned that Olaf had given us her name and location. After few minutes of conversation, we paid the agreed sum (200 pesos ${ }^{2}$ for 30 minutes) in order to hide our identity in front of the brothel owner and traffickers and went to a private room to talk more freely. Only the trafficked woman had knowledge that we were researchers. After the termination of the inter-

$2 \$ 16$ USD. view, we asked her to help us for finding other trafficked women who are working in the same or nearby brothels. At the beginning she declined to help, but after regular interaction she agreed to cooperate to locate other trafficked women. We also promised her to pay 100 pesos per woman in exchange. Whenever she located a woman, she arranged an interview and called us. In this way, applying the snowball technique we were able to gained access and interviewed trafficked women in Monterrey.

Before and during the interviews, we followed the World Health Organization (WHO) ethical and safety recommendations for interviewing trafficked women written by Zimmerman and Watts (2003), including the relevant ethical and methodological procedures such as protection of participant's confidentiality, anonymity, and safety. ${ }^{3}$ It is also necessary to mention here that, although they agreed to the interview via their friend, we always explained ourselves the sole purpose of our study, the subject to be discussed and its risks and benefits in order to gain consent. ${ }^{4}$ Moreover, we never asked any questions that may have caused any emotional reaction, and never questioned their sentiments or judged their decisions or character. In the cases of several women, when they became emotional and preferred not to continue with the interviews, we respected their decision and stopped immediately.

Moreover, at the beginning of the interview, we proposed that the trafficked women come to our house or to any other location of her preference, but they always responded with a "no". They would tell us "...this is our area; it is not possible for us to go out of this place, because the madrina (madam) does not permit us to work in other places...." As the women were not allowed to leave the brothel, we acted as "clients" as this was the only way to gain access to the brothel. Interviews lasted for around 30 minutes and, using the snowball method, a total of 60 women $^{5}$ were interviewed between 2007 and 2013 with a semistructured questionnaire ${ }^{6}$ examining the causes and

${ }^{3}$ The ethical issues of the present research was approved by $e l$ Programa de Apoyo a la Investigación Científica y Tecnológica (PAICYT) of Autonomous University of Nuevo León, Monterrey. The reference number are: DS1613-07 and CS478-10.

${ }^{4}$ We also provided a local telephone number and name of a nongovernmental organization (NGO), where they can get assistance.

${ }^{5}$ Till July 2013 we could interview only 60 women. The fieldwork could not continue because of drug cartel violence in the brothel area. So, for our own security, we stopped the fieldwork.

${ }^{6}$ The questionnaire included topics such as: socio-economic and demographic information of victims, their family background information, mode of trafficking, causes of trafficking, current health problem, violence they suffered during transit and at their destination, information on clients, substances uses, any abortions they have had among others issues. 
consequences of trafficking. Interviews were conducted in Spanish on these topics and were audio-taped. All interviews were transcribed precisely and the information was uploaded to the SPSS program, which served to systematize demographic and socio-cultural information about the trafficked women. We also conducted a discourse analysis to induce a more qualitative sense, noting for example-among others-how age and skin colour are important for trafficking; how the women suffer from violence; how traffickers or the madam treats the; how they were trapped by the traffickers; and their relationship with clients.

\section{Results}

\subsection{Causes and Modes of Trafficking of Women in Monterrey}

Several reasons have been advanced for the incidence and upsurge of trafficking of women. These factors tend to exert pressures on victims that "push" them into migration and hence into the control of traffickers, but other factors that tend to "pull" potential victims can also be significant. The root causes of trafficking of women can also be divided into social, cultural and economic causes, and in this sense it is difficult to underline a specific cause. However, this study suggests that trafficking of women is the result of combination of multiple factors, for example, increasing levels of household poverty, unemployment, domestic violence, infidelity, desertion by a husband, family disintegration, ethnic conflict, intentions of migration to USA, and others (see Figure 1).

Once the trafficker brings out the woman from her place of origin, in most cases he houses her with different intermediaries and gives her training, for example how to establish sexual relation(s), how to negotiate with clients, kinds of dress to wear, and other rules and regulations of the brothel, like not to leave without the permission of the owner, not to talk or reveal any personal information or information regarding others working in the brothel.
From the field work it was found that traffickers use a variety of methods to create a vulnerable condition for the victim so that she cannot decline their offers. One common method is to promise employment and an exotic life in different Mexican cities such as Monterrey, Mexico, Cancun, or in the United States. When a victim gets to know the reality of her employment, she most often refuses to accept. When this happens, pimps and traffickers use various kinds of violence to force women to stay and work in the brothel. Many women describe that their life has become a "life of violence" since they left their home.

Studies reveal that nearly twenty percent (10 women) of trafficked women didn't complete formal education and the rest of them were educated up to primary or above primary level education. In terms of their marital status, fifty three women said that they were unmarried and four women were single mothers but currently not living with their children, whereas only two women were married but separated because of family violence and only one woman was divorced.

Trafficked women in Monterrey were primarily younger; out of sixty women, 75 percent (45 women) were less than 15 years old, 10 women (17 percent) were in between 16 and 20 years old, and only 5 women (8 percent) were more than 20 years old. In this context, the question arises: why there is a high preference for young women and teenage girls? Some research indicates that this preference is largely shaped by socio-cultural factor of machismo, which leads men to seek to affirm certain masculine sexual identities of vitality and dominance (Bimbi, 2014; Durchslag \& Goswami, 2008; ECPAT International, 2005). Additionally, during our conversions with trafficked victim women, it emerged that there is a significantly lower possibility that very young women have already been infected by sexually transmitted diseases, and also from the owner's point of view, these women generate a higher income relative to others. Thus, traffickers are now targeting younger women and girls.

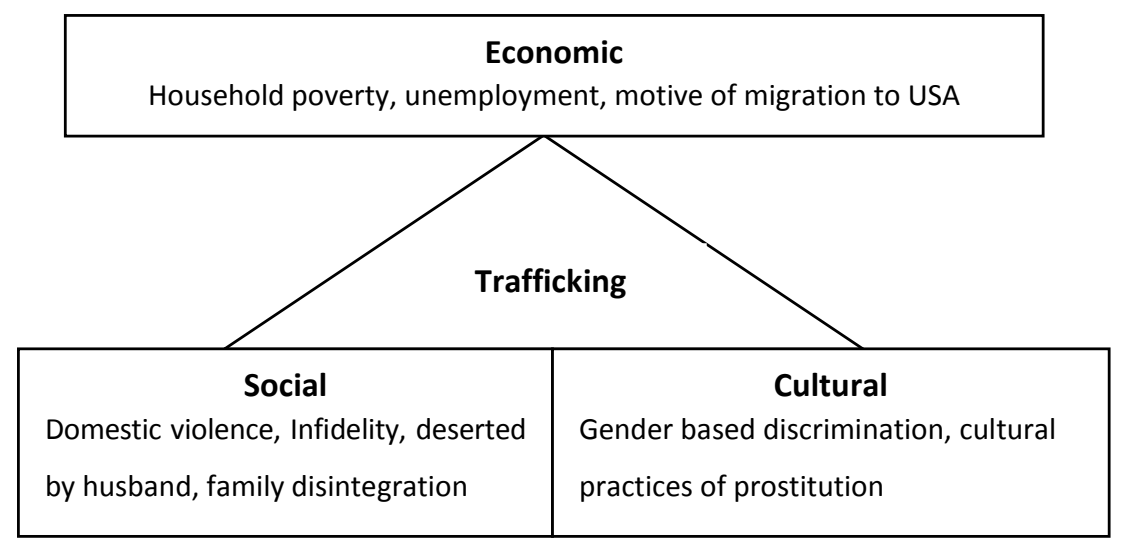

Figure 1. Components of trafficking of women in Monterrey. 
Moreover, Anderson and Davidson (2003) explain the high demand for young women in the sex market as resulting from the fact that the men who seek these girls often do not regard sex with underage girls as "prohibited", rather, they may view these girls and young women as capable of consent and believe that the commercial transaction legitimizes their right to have sexual relations with them. Another significant element that exerts a driving preference on young women is the establishment of consumer society in a patriarchal system. According to Bauman (2000), identities have become more unstable and fragmented and have also become an object of consumption and in the liquid modern consumer society according to neoliberal market principles. By our power to consume we are seduced with the promise that we can become "anybody we like" and this unidentified "anybody" can be purchased.

Since money (or other "benefits") are exchanged, women are deemed to have sold their rights. In our neoliberal market culture, clients are portrayed as "simply" behaving like any other consumer and can ignore the questions of power, human suffering and hardship that form the backdrop to the sex industry. Thus, brothels are treated as a market, where victims are considered as a commodity, and in this place each aspect depends on loss and gain. For example, if a pimp buys a twenty year-old woman, married or divorced, she is less preferred by clients, which means that the pimp cannot obtain optimum earning from the woman. Also, this woman can work in the brothel for a maximum of 4 to 5 years (as women more than 25 years old considered old in this business). Whereas, if a pimp buys a girl of 15 years or less, he can easily make her work for at least 7 to 8 years. Also this young woman will be highly favored and will receive more clients, which will generate a higher profit for the pimp. So, all in all, a brothel owner will earn more money when he buys an unmarried young woman than an older married woman.

\subsection{Violence against Trafficked Women: A New Form of Femicide}

It is a common fact that the victims of violence and sexual violence are overwhelmingly female. Studies on violence against women point to social inequalities in distribution of power, authority and control between men and women as factors (Bimbi, 2014). Dobash and Dobash (1979, in Barnard, 1993) argue in a study of violence against women that the motivations for attacks are often centered on the notions of "keeping a woman in her place". Male role socialization incorporates the notion that women are subordinate, hence men should have right to punish and discipline women (Scully, 1990; Sanday, 1986; Dobash et al., 1992, in Barnard, 1993). Thus, violence is a medium to dominate and suppress a woman, which we can clearly see in case of trafficked women. Studies indicates that trafficked women and commercial sex workers experience high levels of violence, including, but not limited to, physical assaults, sexual assaults, verbal threats, abuse, and psychological abuse (Lowman, 2000; Raymond, 2004).

Information obtained from trafficked women indicates that they suffer both physical and sexual violence from traffickers, pimps and clients. This study has analyzed women who were exposed to physical and sexual violence in three different frequencies, (frequently, occasionally or rarely) in the six months preceding the interview. These levels are categorized as follows: frequent violence, that is aggression faced every day; occasional violence, aggression faced once in two weeks; and rare, violence faced once a month. In the case of frequent violence, it has been observed that women were verbally abused, locked inside a room without food for days, given death threats by pimps, forced to have sex with more than one client at a time, and slapped by pimps as well as by clients. Meanwhile, the study found that women reporting occasional violence were beaten with objects, burnt with cigarettes, raped by pimps, and sometimes pimps even put chili powder in a woman's eyes and vagina. As for those reporting rare violence, pimps burned or stabbed women. Trafficking victims suffer from serious physical abuse and exhaustion, as well as starvation. Some of these serious injuries can cause lasting health problems and may require long-term treatment.

Women who are forced to enter to this profession remain in danger and these kinds of exploitation construct them as victims and, in many cases, they preferred to die rather than continuing there. One 14 year-old girl said: "once I refused to have anal sex with a client due to severe stomach pain, but he didn't respect my body and complained to the padrote (pimp) and asked for his money back. Once the client left the bar, the pimp took me to "el infierno"7 and I was locked in there for a week, and had access only to breakfast and a small bottle of water $(500 \mathrm{ml})$ every day. After a week, when I came out from the room, he warned me not to repeat the same again, otherwise it would end worse. I can say, the day I left my home my life has become so miserable that "at this moment nothing could be sweeter than death". Based on the above discussion, it can be said that trafficked women are treated as mere sexual objects and suffer many and varying abuses and violence from pimps and clients. Thus, looking at severe exploitation and violence, it can be concluded that trafficking is a femicide.

\subsection{Forced Sex and Sexual Exploitation: A Threat to Women's Body}

In the earlier part of this paper, the "objectification of trafficked women", where women are forced into sex

\footnotetext{
${ }^{7}$ Referred to punishment room.
} 
at any point of time, as well as being forced to accept any number of clients per day, has been discussed. In this study, sexual exploitation has been interpreted taking into consideration the number of clients received by a woman in a day and according to her typical sexual relations. Regarding the sexual behavior of trafficked women, some questions were asked during the interview. The information obtained indicates that trafficked women received around ten clients per day, although there were women who had sexual relations with more than ten clients in a day. It also shows that there is an inverse relationship between age and clients received by a woman, that is, the older a woman, the fewer clients she receives per day.

Regarding the sexual activity of trafficked women, some questions were asked including the following: how frequently do clients use condoms during the sexual relations with them and what kinds of sexual relations do clients demand? The study found that clients seldom use condoms because the pimp obligates women to have sex without in order to earn more money $^{8}$ and it is therefore impossible for them to negotiate with client to use a condom. Moreover, women are obligated to practice a wide range of sexual activities at a time as per the client's demands. Some women frequently (everyday) practice vaginal and oral sex with clients, whereas there were women who indicated that they occasional practice anal sex with clients and-very rarely-some clients demand both anal and vaginal sex.

The sexual activity of trafficked woman is directly related to their health. It also encompasses diseases like HIV and STIs/RTIs, sexual dysfunction and problems of unintended pregnancy and abortion. Of the sixty women interviewed, 34 had been exposed to unwanted pregnancy and had an abortion; and twenty six reported having at least one abortion after being trafficked, while eight women had had two or more abortions. According to these women none of these abortions were performed at a clinic; in most cases they had been given some pills by the madam.

However, in addition to sexual activity, the precarious living environment, deficient nutrition, insufficient physical rest and intense physical and psychological violence also result in illness and suffering among trafficked women. The most common health problems among trafficked women are fever, backache, and sleeping disorders. Some women reported that they have irregular menstruation, stomach and back pain during menstruation; some have heavy bleeding during menstruation, pain during intercourse, bleeding after intercourse, lower abdominal pain, abnormal vaginal discharge and a burning sensation while passing urine. The majority of injuries and illnesses reported by women were the result of physical and sexual abuse.

${ }^{8}$ When a woman has sex without condom, the client pays more money.
As discussed earlier, women were beaten, raped, and deprived of sleep, food, and other basic necessities, leading to fatigue and vulnerability to infection, as we can see from the case of Karla, a 23 year-old woman, who was trafficked from Oaxaca state when she was 14 years old. Karla said: for the "last one and half years I have been suffering from severe stomach pain, I have mentioned it to the madam several times, and she always promises to consult with a doctor, but so many months have already passed and she is not paying attention. Last week, when I fell down the staircase, two of her bodyguards came and took me to a room and warned me to not to do that in public. I told them I have severe stomach pain, but they said I am pretending so I don't have to work. Later in the night the madam came and gave me same medicine (which tasted horrible) again and forced me to take it. I took it and after few minutes I felt relaxed. Even for the last few months, I have been having my period every two or three weeks. Though I have told the madam she always said: first I have to earn and deposit a handsome amount with her and then she will take me to the doctor for a checkup. My life has become hell here. For the madam, my pains and feelings are not important, for her I am just an object. I do not know how long I will stay alive. Each day, I feel that my body is degrading, but who can I tell or where can I go".

Meanwhile, when we analyzed the mental health status of the women, it was clearly observed that they are currently suffering complex mental health disorders due to physical and sexual abuse they deal with in their day to day life. In their studies, the International Organization for Migration (2008) and Zimmerman et al. (2008) found that victims of human trafficking, especially women, experience a series of psychological disorders such as recurrent thoughts, recurrent nightmares, feeling detached, trouble sleeping, feeling irritable among others due to the circumstance or condition they are exposed in their daily life. In this regard, we observed in our study that female victims of trafficking in Monterrey suffer from a series of mental health disorders. During the interviews, women cited frequently suffering from anxiety, mood disorders depression, loss of strength, lack of interest, crying, ideas of self-injury or suicide and feelings of guilt. As it discussed earlier, the physical and sexual abuses suffered by women are solely responsible for the development of these emotional disorders.

Moreover, it has been observed that the use of condoms is very rare and women are working in subhuman conditions. They do not have access to proper medical facilities and when women reported any health problems, the madam is the only person who would take them to "consultorio patito"9 (located near

\footnotetext{
${ }^{9}$ Legitimized medical consulting room, but cheap and offering only poor quality service.
} 
the brothel). There are numerous drug stores located close to brothel, where imitation or expired medicines are sold for a cheaper price. If a woman reports a health problem to the madam, she first provides some medicines and then, unless the woman complains again, she never takes her to medical consultation.

\section{Discussion}

Human trafficking has received increasing global attention over the past decade. Initially, the trafficking of women and girls for forced sex work and, to a lesser extent, domestic servitude, were the sole focus of advocacy and assistance. Today, there is more recognition that women, children and men are trafficked into many different forms of labour, and for sexual exploitation. In 1995 at the Beijing Platform for Action (BPFA), trafficking of women was defined as violence against women and, since then, it has been included by all countries in their development strategies. Much has been achieved in terms of clarity of the definition of trafficking, there is also a firm recognition that trafficking is a complex issue and has many ramifications in the related fields of migration, labour and human rights.

From the present study, it may be concluded that trafficking of women in Mexico is a severe human rights violation and is associated with various social, economic and cultural determinants that push young women and girls into human slavery. Results show that it is a complex and serious problem, where women not only run serious social risks of physical and sexual violence, but also have been stigmatized as carrying the main responsibility for the spreading of sexually transmitted diseases and HIV/AIDS. Simply, these women's ability to protect themselves from STDs and HIV/AIDS is drastically weakened by the threat of violence from pimps. Fear of violence exposes trafficked women to many risks such as unprotected sex, unwanted pregnancy, forced sexual relations, mental trauma and substance abuse. Their ability to negotiate regarding the use of condoms by their male partners is inversely related to the extent or degree of abuse in their relationship. Physical and sexual violence against trafficked women has larger consequences on physical, sexual and mental health conditions. It is important to mention that in 2012 Mexico formulated the new antitrafficking law which was reformed by the Mexican senate in March, 2014. Though the present law has provided for severe penalties, incorporates new types of criminal behavior associated with human trafficking, extends the scope of aggravating circumstances of the crime, and increases penalties to up to 30 years imprisonment and fines of 60,000 days' worth of the minimum wage, there are still no concrete policies that have been formulated to combat human trafficking in the country. Thus it can be noted that the gravity of this situation has sent a strong message to the Mexican government due to the nature of exploitation and slavery, which urgently needs to take a comprehensive policy approach, using a combination of the 3Ps: Prevention, Prosecution and Protection to assist victims of trafficking in the country.

\section{Acknowledgement}

This research was funded by the National Council for Science and Technology (CONACYT), Mexico and the University of Nuevo Leon (UANL). The author is grateful to reviewers for their helpful comments that contributed to improving the final version of this paper.

\section{Conflict of Interests}

The author declares no conflict of interests.

\section{References}

Acharya, A. K., \& Stevanato, S. A. (2005). Violencia y tráfico de mujeres en México: Una perspectiva de género. Estudos Feministas, 13(3), 507-524.

Anderson, B., \& Davidson, J. O'C. (2003). Is trafficking in human beings demand driven? A multi-country pilot study. Geneva, Switzerland: International Organization for Migration.

Azaola, E. (2000). Infancia robada. Niñas y niños víctimas de la explotación sexual en México. México: DIF, UNICEF, CIESAS.

Barnard, M. (1993). Violence and vulnerability: Conditions of work for street working prostitutes. Sociology of Health and IIIness, 15(5), 683-705.

Barner, J. R., Okech, D., \& Meghan, A. C. (2014). Socioeconomic inequality, human trafficking, and the global slave trade. Societies, 4(2), 148-160.

Bauman, Z. (2000). Liquid modernity. Cambridge: Polity Press.

Bimbi, F. (2014). Symbolic violence: Reshaping postpatriarchal discourses on gender. Advances in Gender Research, 18-B, 275-301.

Budapest Group. (1996). Anti-trafficking model legislation (Report of the Budapest Group prepared by Belgium and Poland with support of IGC for the meeting of the Expert Group of the Budapest Group, Ljubljana). Vienna, Austria: ICMPD.

Cacho, L. (2010). Esclavas del poder: Un viaje al corazón de la trata sexual de mujeres y niñas en el mundo. Mexico: Grijalbo.

Castillo, D. A., Rangel Gómez, M. G., \& Delgado, B. (1999). Border lives: Prostitute women in Tijuana. Signs: Journal of women in culture and Society, 24(2), 387-422.

Demir J. S. (2003). The trafficking of women for sexual exploitation: A gender-based and well-founded fear of persecution? (Working Paper no. 80). Presented at New issues in refugee research, Evaluation and 
Policy Analysis Unit, United Nations High Commissioner for Refugees, Geneva, Switzerland.

Department of Foreign Affairs and International Trade (DFAIT). (2000). Canadian-US partnership: Building a border for the 21st century. Ottawa, Canada: Department of Foreign Affairs and International Trade.

Durchslag, R., \& Goswami, S. (2008). Deconstructing the demand for prostitution: Preliminary insights from interviews with Chicago men who purchase sex. Chicago: Chicago Alliance against Sexual Exploitation.

ECPAT International. (2005). ¿Mercancía sexual?: Cómo hemos creado la demanda para la explotación sexual comercial de niños, niñas y adolescentes en el Perú. Bangkok, Thailand: ECPAT International.

Farley, M. (2012). Prostitution, trafficking, and traumatic stress. New York, USA: Routledge.

Hadden, G. (2002). National public radio news, reporting from Mexico City: Mexico. Child kidnappings. Retrieved from http://search.npr.org/cf/cmn/ segment_display.cfm?segID=146969

Hernandez, A. (2003, January 11). The sex trafficking of children in San Diego: Minors are prostituted in farm labour camps in San Diego. El Universal.

Herzfeld, B. (2002). Slavery and gender: Women's double exploitation. Gender and Development, 10(1), 50-55.

Heyzer, N. (2002). Combating trafficking in women and children: A gender and human rights framework, UN development fund for women. Paper presented at The Human Rights Challenge of Globalization in Asia-Pacific-US: The Trafficking in Persons, Especially Women and Children, Honolulu, Hawaii.

Hindman, H. D. (2009). The world of child labor: An historical and regional survey. New York, USA: M E Sharpe Inc.

Hughes, D. M., \& Denisova, T. (2003). Trafficking in women from Ukraine. Washington: U. S. Department of Justice.

International Organization for Migration. (2008). Human trafficking in Eastern Africa: Research assessment and baseline information in Tanzania, Kenya, Uganda, and Burundi. Geneva, Switzerland: International Organization for Migration.

International Labour Organization. (2008). ILO action against trafficking in human beings. Geneva, Switzerland: International Labour Organization.

International Labour Organization. (2012). ILO global estimate of forced labour: Results and methodology. Geneva, Switzerland: International Labour Organization.

Jordan, M. (2002, June 30). In Mexico, an unpunished crime. The Washing Post. Retrieved from http:// www.pulitzer.org/archives/6709

Lowman, J. (2000). Violence and the outlaw status of (street) prostitution. Violence against women, 6(9), 987-1011.

Marjan Wijers, L. C. (1997). Trafficking in women, forced labour and slavery-like practices in marriage, domestic labour and prostitution. Utrecht: Foundation against Trafficking in Women and Global Alliance against Traffic in Women.

Martin, S. (2002). Averting forced migration in countries in transition. International Organization for Migration, 40(3), 25-40.

Méndez, R. (2006). Cancún capital del tráfico de mujeres. Revista Contralínea, 1(4). Retrieved from http://www.quintanaroo.contralinea.com.mx/archi vo/2006/agosto/htm/cancun_trafico_mujeres.htm

O'Neill, C. (2010). Immigration and human trafficking in the U.S.-Mexico border region: A conceptual model of the geography of human trafficking, human smuggling, and undocumented immigration (A Frontier Interdisciplinary experience (FIX) Project submitted to New Mexico State University). New Mexico, USA: New Mexico State University.

Observatorio Nacional Ciudadano de Seguridad, Justicia y Legalidad. (2014). Estadística sobre la eficiencia en el combate a la trata de personas en México: Un ejercicio de acceso a la información 2010-2013 (1st ed.). México City: ONC.

Raymond, J. (2004). Prostitution on demand: Legalizing the buyers as sexual consumers. Violence against Women, 10(10), 1156-1186.

Ribando, C.S. (2005). Trafficking in persons in Latin America and the Caribbean (CRS Report for Congress). Washington, DC: Congressional Research Service.

Rusev, A. (2013). Human trafficking, border security and related corruption in the EU (Migration and security sector paper series). Brussels: DCAF.

Sanday, P. (1986). Rape and the silencing of the feminine. In S. Tomaselli \& R. Porter (Eds.), Rape. Oxford: Basil Blackwell.

Shahani, A. (2013, June 14). Human trafficking in Mexico. Quarterly Americas, Americas Society and council of the Americas. Retrieved from http://americas quarterly.org/content/human-trafficking-mexico

Scully, D. (1990). Understanding sexual violence: A study of convicted rapists. London: Harper Collins.

Timothy, P. (2001, January 11). Sex slavery racket a growing concern in Latin America. Christian Science Monitor. Retrieved from http://www.csmonitor. com/2001/0111/p7s1.html

U.S. State Department. (2014). Trafficking in persons report. Washington: U.S. State Department.

United Nations General Assembly. (2000). Protocol to prevent, suppress and punish trafficking in persons, especially women and children, supplementing the United Nations Conventions against transnational organized crime (adopted in 15 November 2000, G.A. Res. 25, annex II, U.N. GAOR, 55TH Sess., Supp. No. 49, at 60, U.N. Doc. A/45/49 (Vol. I) (2001), entered into force 25 December 2003). New York: United Nations. 
United Nations Office on Drug and Crime. (2012). Global report on trafficking in persons 2012 (Sales No. E.13.IV.1). New York: United Nations.

Walters, J., \& Davis, P. H. (2011), Human trafficking, sex tourism, and child exploitation on the southern border. Journal of Applied Research on Children: Informing Policy for Children at Risk, 2(1), article 6.

Wennerholm, C. J. (2002). Crossing borders and building bridges: The Baltic Region Net-working project, Gender and Development, 10(1), 10-19.

World Health Organization. (2012). Human trafficking. Switzerland: World Health Organization. Retrieved from http://apps.who.int/iris/bitstream/10665/773 94/1/WHO_RHR_12.42_eng.pdf

Zheng, T. (2013). Ethical research in a fraught environ- ment. In Dewey, S. \& Zheng, T. (Eds.), Ethical research with sex workers anthropological approaches (1st ed.). New York, NY: Springer.

Zimmerman, C., \& Watts, C. (2003). WHO ethical and safety recommendations for interviewing trafficked women. Geneva, Switzerland: World Health Organization.

Zimmerman, C., Hossain, M., Yun, K., Gajdadziev, V., Guzun, N., Tchomarova, M., Ciarrocchi, R. A., Johansson, A., Kefurtova, A., Scodanibbio, S., Motus, M. N., Roche, B., Morison, L., \& Watts, C. (2008). The health of trafficked women: a survey of women entering post-trafficking services in Europe. American Journal of Public Health, 98(1), 55-59.

\section{About the Author}

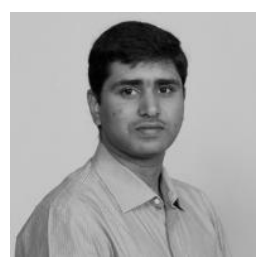

\section{Dr. Arun Kumar Acharya}

Dr. Arun Kumar Acharya is professor in demography at the Institute for Social Science Research at Autonomous University of Nuevo Leon, Monterrey, Mexico. He has published various research papers in various international journals on the issue of Migration, Trafficking and Gender violence, also books on Migration and Human trafficking in Mexico. He is also member of International Union for Scientific Study of Population (IUSSP). 